\title{
Crítica Literária na escola: caminhos e descaminhos
}

\section{Literary Criticism in schools: paths and detours}

https://doi.org/10.34112/2317-0972a2016v34n68p65-78

Júlio de Souza Valle Neto ${ }^{1}$

Resumo: Este artigo pretende discutir o papel da Crítica Literária em contexto escolar, investigando as razões de seu uso relativamente pequeno em sala de aula e propondo uma abordagem específica para o Ensino Médio.

PALAVRAS-chaVe: Letramento literário; crítica literária; leitura.

ABSTRACT: This article addresses the role of Literary Criticism in a school context, exploring the reasons for its relatively small use in the classroom and proposing a specific approach to be used in High School.

KEYWORDS: Literary literacy; literary criticism; reading.

TEORIA, HISTÓRIA E CRÍTICA LITERÁRIAS: REVISITANDO FRONTEIRAS

Teoria, História e Crítica Literárias sugerem modos distintos para o estudo do texto. Como formas do estudo de obras e autores, é natural que cada uma delas deixe as suas marcas, mais ou menos visíveis, no processo de escolarização da literatura. Nesse percurso específico, o exame de tais rastros revela, a olho nu, a nítida presença das duas primeiras. Especialmente a História Literária reitera, no âmbito

1. Universidade Federal de São Paulo (UNIFESP), Guarulhos, SP, Brasil. 
escolar, um prestígio vivo e atuante, apesar da desconfiança inspirada na academia, há bom tempo, pelos modelos narrativos caudatários da historiografia. Ao mesmo tempo, a Crítica apresenta, nesse trajeto particular, contornos apenas esmaecidos e ocasionais: numa determinada ótica, pode-se dizer que ela constitui o ramo mais desprestigiado dos estudos literários na escola.

Antes de sustentar essa hipótese, convém recusar, logo de início, a impressão de que tais formas de estudo literário se apresentam estanques. Apesar de distintas, elas não configuram propostas de exploração impermeáveis. Como observa Antoine Compagnon (2014, p. 222),

[...] mesmo a história literária mais restrita, fixada unicamente nos fatos, repousa ainda em julgamentos de valor, quando nada devido à decisão prévia, o mais das vezes tácita, sobre o que constitui a literatura (o cânone, os grandes escritores). As abordagens mais teóricas ou descritivas (formalista, estrutural, imanente), queiram ou não, também não escapam da avaliação, que muitas vezes é, aí, fundamental. Toda teoria, pode-se dizer, envolve uma preferência, ainda que seja pelos textos que seus conceitos descrevem melhor, textos pelos quais ela foi provavelmente instigada (como ilustra a ligação entre os formalistas russos e as vanguardas poéticas, ou entre a estética da recepção e a tradição moderna).

Ao mesmo tempo em que assinala a inevitável impureza de cada uma das disciplinas, Compagnon reitera, de modo mais ou menos indireto, o escopo de atuação preferencial da História, da Teoria e da Crítica Literárias. Assim, como observa o mesmo autor em outra obra, Literatura para quê?, a História Literária - comparável à filologia - apega-se "às obras no que elas têm de único e singular, de irredutível e de circunstancial (um texto, um autor), ou no que elas tem de serial (um movimento, uma escola) e explicam-nas por seu contexto" (COMPAGNON, 2009, p. 15). A Teoria Literária, por seu turno, bifurca-se em duas descrições-chave ("crítica da ideologia, análise linguística"), que "se fortalecem mutuamente, pois a crítica da ideologia é uma denúncia da ilusão linguística [...]: a teoria literária expõe o código e a convenção ali onde a teoria postulava a natureza" (COMPAGNON, 2014, p. 24). Por fim, ao referir-se à "crítica”, o mesmo autor a define, em outra oportunidade, por meio de um aposto cristalino: "quero dizer, o julgamento ou a avaliação” (COMPAGNON, 2009, p. 23). Retoma-se, de forma indireta, a sugestão etimológica do termo, que remete à ação de discernir - ou, como parece evidente, valorar. Como lembra Roberto Acízelo de Souza (2003, p. 145) - remetendo, por sua 
vez, a René Wellek -, "ainda hoje” a acepção mais corrente da disciplina reafirma a ideia fortalecida no século XIX: "um sistema escalonado de saber sobre literatura, que envolve, como operação de cúpula, a emissão de juízos de valor sobre obras e autores (cf. Wellek, s/d., p. 29-41, passim)."

Retomados os campos de atuação preferencial de cada disciplina, pode-se compreender melhor como se dá a recíproca "contaminação", por assim dizer, entre umas e outras. A Teoria Literária, mesmo quando eventualmente "descritiva" (e propensa à análise linguística, a exemplo do formalismo russo), não escapa de uma valoração anterior, responsável pela eleição de um dado corpus e de uma dada exploração analítica. Do mesmo modo, como observa Compagnon (2014), o próprio conceito de "literatura" é capital para o teor dos eventos descritos pela História Literária. Segundo Acízelo de Souza (2003, p. 146), é frequente deparar-se, no discurso historiográfico, com "julgamentos explícitos" ou "decisões críticas nem sempre declaradas como tal, caso, por exemplo, da exclusão de determinado autor ou obra do conjunto de 'fatos' estudados, bem como da variação do grau de atenção concedida aos escritores incluídos [...]". Donde se conclui que a Crítica, tal qual definida anteriormente, faz-se presente de forma implícita em ambas as disciplinas. Portanto, se ela é o ramo mais desprestigiado dos estudos literários na escola, como se propôs há pouco, isto não significará propriamente ausência, mas, muitas vezes, presença fantasmal.

TEORIA, HISTÓRIA E CRÍTICA LITERÁRIAS NA ESCOLA: EXPLORANDO OS LIVROS DIDÁTICOS

Já faz alguns anos, a História Literária vem enfrentando restrições em relação à pertinência de sua aplicação no ensino de literatura. Os Parâmetros Curriculares Nacionais, publicados em 1999, preconizavam o seu deslocamento hierárquico, a partir daquele momento, para "um segundo plano" (BRASIL, 1999, p. 38). A afirmação categórica contradizia-se poucas páginas depois, quando se demandava do estudante, entre as poucas "competências e habilidades" claramente vinculadas à literatura, a capacidade de "recuperar, pelo estudo do texto literário, as formas instituídas de construção do imaginário coletivo, o patrimônio representativo da cultura e as classificações preservadas e divulgadas, no eixo temporal e espacial" (BRASIL, 1999, p. 24).

Passados quinze anos, algo dessa ambiguidade permanece plenamente visível. O Guia de Livros Didáticos PNLD 2015, por exemplo, apresenta ao professor dez resenhas de obras aprovadas pelo Programa Nacional do Livro Didático. No tocante 
à literatura, a apresentação da matéria segundo um critério cronológico é traço comum a praticamente todos os livros selecionados. A já tradicional operação de vincular um texto-exemplo aos traços gerais de um determinado estilo de época também se faz claramente presente no corpus selecionado. Por outro lado, também é visível, nas resenhas em questão, a preocupação em valorizar as propostas menos tradicionalistas nesse âmbito, por assim dizer, tão tradicional do ensino de literatura. Assim, a leitura efetiva dos textos literários é ponto a favor nas coleções de vetor historiográfico mais evidente (cuja implementação se vê frequentemente substituída, nos piores casos de instrumentalização da História Literária, por trechos de contextualização histórica autônomos e generalistas). De qualquer maneira, o eixo do trabalho com a disciplina permanece, ainda, claramente serial e classificatório. Demonstração, mais uma vez, da decisiva influência desempenhada por um dado uso da História Literária (e a modalização aqui é importante) no ensino de literatura no Brasil - especialmente no Ensino Médio. O cenário, ao que parece, reflete em parte a recomendação, ao mesmo tempo clara e dúbia, dos mencionados PCN.

Um breve olhar sobre a situação da Teoria Literária revela, igualmente, uma presença marcante sobre a escolarização da literatura. "Crítica da ideologia" e "análise linguística”, como propõe Compagnon (2014), a escola tende a privilegiar claramente a segunda de suas inflexões. Tomando-se novamente o universo dos livros didáticos como referência, o exame do primeiro volume de Linguagem em Movimento (TORRALVO; MINCHILLO, 2010) fornece um modelo frequente de incorporação da Teoria Literária ao ensino. Num capítulo inicial, de caráter introdutório ("Introdução à Literatura"), apresentam-se os fundamentos capitais da literatura. No livro em questão, chega-se mesmo a referir, textualmente, "a noção de estranhamento", desentranhada, como se sabe, do formalista russo Viktor Chklovski. Tendo fornecido o material introdutório para a disciplina, a Teoria Literária é convocada, neste e ao longo dos demais volumes, a municiar o aluno com o arsenal analítico próprio ao embate com os textos literários. Assim é que, visando ao trato com os textos poéticos - mas não só -, tem lugar a exposição das tradicionais figuras de linguagem (metáfora, catacrese, antítese, paradoxo etc.), assim como, visando ao trato com os textos em prosa - mas também não só -, abordam-se, em capítulos espaçados, o "estudo do foco narrativo" e o das "personagens na narrativa".

Ao contrário do verificado com a Teoria e História Literárias, a Crítica não se revestirá do mesmo caráter sistemático na disciplina de Língua Portuguesa, apresentando-se, quase sempre, de modo lateral e assistemático. Assim, o segundo volume 
de Português: Ensino Médio, de José de Nicola, ilustra um procedimento razoavelmente frequente nas publicações do gênero: amparar a breve apresentação de uma obra (ou de um autor) no juízo crítico de um renomado estudioso (ou, por vezes, escritor). Desse modo, convoca-se Mário de Andrade para referendar a classificação do célebre livro de Manuel Antônio de Almeida enquanto "romance de costumes": para o modernista, "um dos grandes méritos das Memórias de um Sargento de Milícias é ser um tesouro muito rico das coisas e costumes das vésperas da Independência" (NICOLA, 2005, p. 327). A citação limita-se a embasar a classificação proposta, não ensejando, por exemplo, nenhuma reflexão acerca do critério de valoração implícito na avaliação (ou seja, o de que um livro se reveste de importância literária ao agir, também, como documento histórico), ou, ainda, alguma consideração acerca da compreensível boa vontade do modernista em relação ao romance. Afinal, ambos comungam, no interior de seus respectivos momentos históricos, do mesmo propósito de realçar os vínculos entre literatura e vida social. Nesse sentido, o elogio de Mário pode ser compreendido como uma espécie de afirmação bumerangue, já que retorna, de algum modo, para o próprio crítico enquanto escritor modernista. O juízo de valor, portanto (e reiteramos que o livro em pauta não é exceção, mas regra), comparece enquanto naturalização de um dado tipo de conhecimento (mais precisamente, de ordem taxionômica, remetendo ao "romance de costumes"), mas não enquanto instância necessariamente parcial da apreciação literária (o que, de resto, estende-se em maior ou menor grau a qualquer operação do gênero).

Eventualmente, a Crítica tem lugar, nos livros didáticos, de forma a abranger a questão do gosto, cuja importância, como se verá adiante, parece evidente. Por ora, basta referir, a título de exemplo, a proposta de reflexão formulada por João Domingues Maia em Português (2004). Sob o tópico "Intertextualidade", transcreve-se um trecho de Cinco Minutos, de José de Alencar, pouco depois de o capítulo abrir-se com a transcrição de "O Primeiro Beijo", capítulo de Memórias Póstumas de Brás Cubas. Pergunta-se, então, se o aluno "encontrou um certo exagero que torna o texto piegas, isto é, ridiculamente sentimental", bem como se, "ao ler este texto", "uma leitora do século XX ou XXI teria as mesmas emoções de uma leitora do século XIX" (MAIA, 2004, p. 270). A atividade, rica em possibilidades de discussão, aponta para a historicidade da forma (e para a conseguinte relativização do gosto e do valor). De qualquer maneira, ela permanece enquanto ocorrência ocasional e passageira - e é dever assinalar que, entre os dois tipos de exploração aqui mencionados, a primeira é sem dúvida a mais corrente. 
A CRÍtica NOS DOCUMENTOS OFICIAIS: UMA PRESENÇA FUGIDIA

Muito desse cenário explica-se, possivelmente, pela situação relativamente delicada da Crítica, quando comparada à da Teoria ou História Literárias, em contexto escolar. Como se verificou páginas atrás, estas últimas prestam-se mais docilmente ao processo de escolarização, na medida em que a primeira oferece um instrumental de análise e, a segunda, uma narrativa encadeada de fatos supostamente relevantes para o bom domínio da disciplina. Dito de outro modo, ambas se prestam, claramente, à tendência escolar de fechar currículos e quantificar saberes. Já a Crítica Literária, na medida em que traz para o centro da discussão a questão do valor, opõe uma zona de conflito, ao menos potencial, a essas demandas institucionais: afinal, ao propor como instância de reflexão a valoração dos objetos literários, ela propõe, por tabela, uma instância de reflexão acerca do próprio currículo.

O exame das relações entre a questão do valor e os documentos que norteiam, no Brasil, o currículo do Ensino Básico, revela de fato uma situação algo contraditória. Nos primeiros $P C N$ para o Ensino Médio, lê-se a certa altura a seguinte proposição: "O conceito de texto literário é discutível. Machado de Assis é literatura, Paulo Coelho não. Por quê? As explicações não fazem sentido para o aluno” (BRASIL, 1999, p. 34). Como se vê, a questão envolve o papel desempenhado pelo valor sobre a própria constituição do literário, fazendo lembrar a oposição, hoje um tanto démodée, entre "literatura" e "subliteratura". Ocorre que, da maneira como está formulada - e, sobretudo, da maneira como se deixa abruptamente interromper-, a proposição acaba por referendar uma deslegitimação apriorística da ideia de valor. Desse modo, a aparente tentativa de transplantar o debate acerca de sua pertinência, corrente na academia, para o intramuros da escola, traduz-se quando muito na assunção de um axioma relativista. Embora formalmente se propondo a problematizar os critérios de valoração estética - o que implica, tão somente, submetê-los a uma contextualização sócio-histórica -, o documento acaba por descartá-los, de antemão, enquanto construções ideologicamente interessadas (PERRONEMOISÉS, 2006, p. 23-24). Dito isso, não surpreende que uma das consequências dos Parâmetros, como observa Rildo Cosson, tenha sido avalizar uma espécie de indistinção generalizada dos objetos estéticos, segundo a qual o cânone tradicional e o "do mercado", eventualmente, podem nivelar-se de forma acrítica (COSSON, 2004, p. 97). Em suma, o valor parece agir, nesse contexto, mais como um vazio conceitual do que como um conceito curricularmente passível de escolarização. 
Felizmente, os chamados $\mathrm{PCN}+$, documento que se segue aos primeiros $\mathrm{PCN}$, tomam a questão em termos bastante mais ponderados. Aqui, a partir do estudo das "premissas" atuantes, historicamente, nos "juízos críticos sobre manifestações culturais", prevê-se o desenvolvimento mais consistente de competências valorativas no aluno (BRASIL, 2002, p. 65). Por sua vez, as mais recentes Orientações Curriculares para o Ensino Médio (OCEM) propõem em vários sentidos uma revisão dos primeiros PCN (a começar do tratamento, em separado, dos "Conhecimentos de Literatura" e dos "Conhecimentos de Língua Portuguesa", como forma de recuperar "a autonomia e a especificidade" dos estudos literários (BRASIL, 2008, p. 49). No tocante ao valor, especialmente, as Orientações deixam claramente expresso que, em âmbito escolar, os textos literários, canônicos ou não, para além de "serem significativos dentro de determinado contexto", também devem revelar "qualidade estética” (BRASIL, 2008, p. 57). Como se vê, a abertura ao relativismo, apreensível dos primeiros Parâmetros, parece contradita pelo documento.

Naturalmente, a sucessão de prerrogativas curriculares torna menos claro o caminho a ser seguido, na medida em que a própria barafunda de documentos denuncia a inexistência de clareza acerca do que, nesse âmbito, é central e periférico. Não espanta, nesse sentido, que Neide Luzia Rezende, uma das autoras das Orientações, declare que o texto permaneça "curiosamente ignorado em prol dos antigos PCNEM" (REZENDE, 2013, p. 111). Especificamente no tocante à Crítica, entendida como operação valorativa específica, o diagnóstico parece confirmar-se, na medida em que, como disposto há pouco e na esteira do que sugerem os PCN, ela tem figurado, reitere-se, como uma espécie de vazio conceitual.

UMA PROPOSTA DE TRABALHO EM SALA DE AULA: CRÍTICA E ESTUdos DE CASO

Para explicitar de que modo a Crítica Literária poderia, de fato, inscrever-se de forma justificável no dia a dia escolar, convém ter em mente, antes de mais nada, a acepção com a qual se pretende abordá-la nesse contexto. É importante tomá-la do modo mais claro possível, enquanto forma de avaliação atuante, historicamente, no processo de valoração dos objetos artísticos. Devidamente integrada ao cotidiano do trabalho com a literatura, o objetivo é que ela se traduza, pouco a pouco, num modo de leitura específico, isto é, numa apropriação do texto literário capaz de abarcar, produtivamente, a questão do valor. Em termos pedagógicos, como se verá em 
seguida, essa proposta contempla tanto a leitura quanto a produção textual (que não se restringe, como preconiza a concepção de "texto" corrente nos PCN, ao registro escrito ou mesmo verbal).

Tomar a Crítica enquanto objeto cotidiano no trabalho com a literatura signifi$\mathrm{ca}$, antes de mais nada, lidar com estudos de caso específicos. Tomemos dois autores como exemplo, iniciando pela obra de Jorge Amado. Na escola, é comum reiterar-se o sucesso de seus livros, inclusive no exterior, bem como insistir na integração de seus romances, num determinado momento, ao neorrealismo da década de 1930 - o que dá conta da habitual catalogação histórico-literária corrente no Ensino Médio. Menos frequente, entretanto, é explorar em sala de aula o discutível valor de sua obra literária, cujo arco varia da aprovação à reprovação exacerbadas. Exemplo desta última tendência é a avaliação de Alfredo Bosi, conforme se lê em sua História Concisa da Literatura Brasileira (um bom exemplo, aliás, de como Crítica e História Literária se dão frequentemente as mãos):

Cronista de tensão mínima, soube esboçar largos painéis coloridos e facilmente comunicáveis que lhe franqueariam um grande e nunca desmentido êxito junto ao público. Ao leitor curioso e glutão a sua obra tem dado de tudo um pouco: pieguice e volúpia em vez de paixão, estereótipos em vez do trato orgânico dos conflitos sociais, pitoresco em vez da captação estética do meio, tipos 'folclóricos' em vez de pessoas, descuido formal a pretexto de oralidade... Além do uso às vezes imotivado do calão: o que é, na cabeça do intelectual burguês, a imagem do eros do povo. $\mathrm{O}$ populismo literário deu uma mistura de equívocos, e o maior deles será por certo o de passar por arte revolucionária. No caso de Jorge Amado, porém, bastou a passagem do tempo para desfazer o engano. (BOSI, 1994, p. 406).

Por outro lado, sob a manchete "Jorge Amado segundo a crítica literária", o site do Jornal do Comércio noticia, em matéria de agosto de 2012, que "o escritor começa a ser avaliado com mais justiça”. Balizam esta percepção dois professores universitários. Um deles, Eduardo de Assis Duarte, explica a resistência da Crítica por sua "formação completamente modernista", donde a hostilidade com uma obra herdeira, em parte, "das narrativas do século 19 [...] e que dialoga com o público". Para outro pesquisador, Anco Márcio Tenório Vieira, o papel desempenhado pela sexualidade, nas obras do escritor, nem sempre foi bem avaliado: "É nesse quadro que Amado mais transige. Ou seja, é onde as tensões sociais e econômicas são 
amainadas, embaralhadas, parecem perder força. É onde Eros vence o Logos”. Por isso, seria possível estabelecer, para o professor, um paralelo entre o romancista e Nelson Rodrigues, pois ambos teriam explorado, literariamente, "a dualidade entre a moral da casa, aquela que é a da aparência, e a moral da rua, a das pulsões sociais".

O segundo estudo de caso, aqui, é bem conhecido, apesar de pouco explorado na escola: a desaprovação que Machado de Assis dirige ao clássico de Eça de Queirós, O Primo Basílio. Para o brasileiro, o sucesso do romance se explicaria, como lembra Paulo Franchetti (1998, p. 23), pelo gosto rebaixado do público daquele período, ao qual satisfazia plenamente "a literatura baixa do Naturalismo". Além disso, Machado reprova a concepção de Luísa, cujo adultério não encontraria, "no nível da narrativa", nada que o justificasse: por isso, "a personagem lhe parece uma construção abstrata da vontade do autor” (FRANCHETTI, 1998, p. 26). É curioso notar como também nesse caso, portanto, recrimina-se o "leitor curioso e glutão", faminto por cenas quentes, a despeito de sua alegada gratuidade na estrutura da obra.

Tomadas em conjunto, a abordagem desses juízos críticos poderia interessar, ao aluno, em vários níveis. Em primeiro lugar, revelando a existência de um critério técnico de avaliação estética, a saber, o prejuízo da unidade por conta da identificação de "pontas soltas": é o que Bosi recrimina em Jorge, acusando-lhe de "uso imotivado do calão", e Machado em Eça, reprovando a aparente imotivação para o adultério de Luísa. Em segundo, realçando a relatividade de tais critérios, na medida em que a impressão de gratuidade, nos dois juízos negativos, pode advir de uma parcialidade do crítico (é o que Franchetti aponta no caso de Machado, cuja perspectiva lhe parece bastante "interessada", e o professor Vieira, por seu turno, no tipo de leitura feita por Bosi, à qual foge o papel legítimo desempenhado pela sexualidade na obra de Amado: explorar a dualidade entre a "moral da casa" e a "moral da rua".). Em terceiro, propiciando uma incorporação mais rica de aspectos da História Literária, seja para discutir a validade do padrão modernista atuante na avaliação do escritor baiano (patente no descompasso entre as expectativas acadêmicas, mais afins ao vanguardismo oswaldiano de Miramar, e a prosa fluente de Jorge, mais próxima de esquemas narrativos tradicionais, de maior penetração popular), seja para refletir sobre os pressupostos românticos que, naquela altura, ainda inspiram as ressalvas machadianas ao Naturalismo (patentes, por exemplo, na defesa da "arte pura" contra a "impura" (FRANCHETTI, 1998, p. 25). Por fim, explicitando que o divórcio entre crítica e público, como mostram a consagração de Eça e a crescente aceitação 
acadêmica de Jorge, não configura um dado incontornável, mas explicável e variável segundo injunções históricas específicas.

Contudo, os maiores trunfos advindos desse tipo de discussão, levando-se em conta o cenário predominante no ensino de literatura, seriam basicamente dois. Em primeiro lugar, seria evitada a mensagem que, talvez inadvertidamente, a escola costuma transmitir ao aluno reticente diante do valor dos textos correntes nesse universo. Via de regra, tal reticência é compreendida de modo unilateral: ela acomete unicamente a figura do aluno, incapaz de compreender, por imperícia de leitor iniciante, a reconhecida importância do que tem em mãos. Incorporar ao cotidiano das salas de aula tópicos como os advindos da recepção crítica de Eça e Amado significa, inversamente, recusar a dicotomia tão escolar entre o certo e o errado: reconduzindo para o domínio do especialista a dúvida acerca do valor, a mensagem deixa de ser condenatória para tornar-se, ao mesmo tempo, pedagogicamente mais solidária e intelectualmente mais honesta. Isso leva, naturalmente, ao segundo trunfo, pelo qual se torna evidente que essa solidariedade nada tem a ver com permissividade. Tomando o estudo do valor a partir de estudos de caso específicos, recusa-se como suficiente o axioma segundo o qual tudo é relativo e subjetivo - e do qual costuma advir, como observa Rildo Cosson (2004), a aceitação indiscriminada de toda e qualquer avaliação. A familiaridade com as limitações da Crítica revela o quanto ela é, necessariamente, parcial, mas não arbitrária: ela precisa tomar partido (com maior ou menor grau de consciência), mas também precisa justificá-lo.

\section{CONSIDERAÇÕES FINAIS: CRÍTICA, LEITOR COMUM E BONS EXEMPLOS}

Uma vez que essa proposta de trabalho implica a presença, eventualmente, de juízos advindos de especialistas (e dos conceitos-chave que os embasam), o temor do tecnicismo pode aflorar, aqui, com maior força. Tomando-se inicialmente o conjunto mais restrito de reflexões desenvolvido há pouco, contudo, esse temor poderia se justificar, com mais sentido, quanto ao terceiro tópico, dedicado a combinar a questão dos juízos de valor com as variantes histórico-literárias a eles subjacentes. Ainda aqui, esse inconveniente se resolve tão somente pela inclusão da discussão em momento propício, ou seja, quando essas categorias já forem familiares ao estudante. Satisfeito esse pré-requisito (de preferência, como nunca é demais lembrar, pela experiência de leitura efetiva, ao longo do percurso escolar, de textos românticos e modernistas), esse único tópico sensível, dentre os quatro citados, poderia 
transcorrer de modo produtivo em sala de aula. Seja como for, a restrição é útil para lembrar que, para o bom andamento dos estudos de caso, é imprescindível operar com uma seleção criteriosa de textos críticos, propícios à exploração pedagógica naquele dado universo de alunos. Cuidado, aliás, que deve balizar a própria escolha dos textos literários na escola, como também nunca é demais lembrar.

Além disso, o risco do tecnicismo não é uma realidade, apenas, para a Crítica: ele afeta, igualmente, o modo como a Teoria e a História Literárias se traduzem em componentes curriculares. Se assim é, a questão se torna, necessariamente, mais geral: afinal, o que é excessivo, em termos de técnica, no ensino de literatura? Certamente, não será admitir que a escola é o lugar, por excelência, em que conhecimentos advindos dessas disciplinas devem ter circulação. Mas será, isso sim, tudo aquilo cuja presença justifica-se per se - e não pelo que pode representar de enriquecimento de leitura ${ }^{2}$. Nesse sentido, a Teoria Literária é excessiva quando obriga o aluno a decorar o que vem a ser "sinédoque" - sem, contudo, investigar os efeitos de sentido, em textos literários determinados, que a figura de linguagem produz. A História Literária, por seu turno, é excessiva quando reduz o texto a mero sintagma do paradigma tipológico-historiográfico (sem, inclusive, atentar para os limites que os textos, sobretudo os inovadores, impõem à descrição geral). E a Crítica, finalmente, será excessiva quando admitir que, na escola, está formando futuros críticos literários - e não leitores comuns que podem vir a se beneficiar, contudo, de noções acerca do valor artístico.

Em grande medida, esse enriquecimento de leitura, propiciado pela Crítica, traduz-se no próprio conhecimento dos processos que levam à sempre relativa cristalização do cânone, dedicando-se especial atenção para a sua descontinuidade (que faz de $O$ Primo Basilio, inicialmente, um livro tido como apelativo por Machado de Assis - adjetivo que, décadas depois, qualificaria também, para alguns, a obra de Jorge Amado). Em outras palavras, mesmo os clássicos, em maior ou menor medida, passam a ser compreendidos, no interior do universo escolar muitas vezes tendente à sacralização, como expressão de "consensos parciais" (COMPAGNON, 2014, p. 250). Abordar esse processo no trabalho cotidiano com a literatura, ao invés

2. Ou, para dizer com Maria Amélia Dalvi (2013, p. 81): "Nos últimos anos do ensino fundamental e, sobretudo, no ensino médio, torna-se indispensável, porém, fornecer aos alunos termos e conceitos fundamentais das gramáticas, da linguística, da genologia, da retórica e da poética, da história, da crítica e da teoria literárias mostrando, a partir dos textos e com os textos, sua utilidade e contribuição no processo de leitura - sem isso, são desnecessários". 
de amarrar a recepção do leitor a um simples "certo" (isto é, endossar o clássico) ou "errado" (ou seja, refutá-lo enquanto texto "chato" ou ultrapassado), recoloca a leitura individual num quadro receptivo muito mais amplo, no qual têm lugar diferentes vozes e contextos sócio-históricos. Assim, a voz do aluno que acaba de ler pela primeira vez Capitães da Areia pode dialogar, por exemplo, com as restrições emitidas por Bosi ou as ponderações de Vieira e Duarte. O confronto colabora para um duplo conhecimento, na medida em que o aluno toma contato, de um lado, com o modo pelo qual ele próprio agencia adesões ou restrições frente uma obra específica e, de outro, com as diferentes estratégias interpretativas através das quais se confere mais ou menos valor a uma dada obra. Se, como propõem as OCEM, cumpre à escola "formar para o gosto literário" e "oferecer instrumentos para uma penetração mais aguda nas obras" (BRASIL, 2008, p. 69), ao que parece, a incorporação da Crítica ao letramento literário na escola, nesses moldes, concorre em parte para a consecução desses objetivos.

Não estando, pois, empenhada em formar críticos profissionais, a escola pode se valer de formas pelas quais essas incursões críticas, de modo diverso ao padrão corrente na academia, contemplem modos de veiculação para além do texto escrito. Nesse grupo, desempenham papel de relevo os vídeos produzidos para esse fim, muitos dos quais disponibilizados no Youtube. É possível encontrarem-se resenhas, no site, de clássicos como o romance $O$ Ateneu, de Raul Pompéia, e $O$ Cortiço, de Aluísio Azevedo. Geralmente produtos de trabalhos escolares, os vídeos ilustram um tipo de iniciativa na qual a Crítica literária, ainda que menos presente do que a História e a Teoria, pode encontrar um canal pertinente de reflexão na vida escolar.

Por fim, ainda no rol de iniciativas minoritárias dignas de nota, cabe mencionar o livro de Heloísa Harue Takazaki, Língua Portuguesa (2005). De modo contrário ao observado na quase totalidade dos livros didáticos, aqui a autora dedica dois capítulos à discussão do valor literário: o décimo quinto denomina-se, justamente, "Os clássicos" e propõe discussões acerca do conceito, partindo tanto das definições consagradas nos dicionários quanto de excertos do famoso ensaio de Ítalo Calvino, Por que ler os clássicos?; o seguinte, por seu turno, intitula-se "Resenhas" e dispõe juízos contrastantes sobre a obra de Machado de Assis (incluindo a famosa diatribe de Sílvio Romero contra esse "pernicioso enganador"), assim como apreciações díspares, correntes na imprensa, sobre a adaptação cinematográfica de Memórias Póstumas de Brás Cubas. Aliás, nesse último caso, uma das questões propostas define o cânone como "uma espécie de padrão ao qual nos habituamos e que acaba 
por determinar nossas preferências", para depois indagar se "é possível que os dois críticos que escreveram as resenhas tenham usado cânones diferentes para analisar a mesma obra” (TAKAZAKI, 2005, p. 186). Uma questão, como se vê, muito semelhante àquela, mencionada há pouco, sobre os diferentes cânones críticos implicados na aprovação ou reprovação da obra de Jorge Amado. Ocorrências como essa animam duplamente, seja mostrando que a Crítica, ainda que relativamente desprestigiada, não deixa de inspirar, ocasionalmente, reflexões produtivas no trabalho com a literatura na escola, seja realçando a sua viabilidade enquanto estratégia, pedagogicamente justificada, de enriquecer a leitura de textos literários em sala de aula. Foi, ao menos, o que se pretendeu demonstrar nessas páginas.

\section{REFERÊNCIAS}

BOSI, A. História concisa da literatura brasileira. 3. ed. São Paulo: Cultrix, 1994.

BRASIL. Parâmetros curriculares nacionais: ensino médio: Linguagens, códigos e suas tecnologias. Brasília: MEC/SEMTEC, 1999. . PCN+ Ensino Médio: Orientações educacionais complementares aos Parâmetros curriculares nacionais: Linguagens, códigos e suas tecnologias. Brasília: MEC/SEMTEC, 2002. . Orientações curriculares para o Ensino Médio: Linguagens, Códigos e suas Tecnologias. Brasília: MEC/ SEB, 2008. . Guia de livros didáticos PNLD 2015: Português. Brasília: MEC/ SEB, 2014.

COMPAGNON, A. Literatura para quê? Trad. Laura Taddei Brandini. Belo Horizonte: Editora UFMG, 2009.

. O demônio da teoria: literatura e senso comum. Trad. Cleonice Paes Barreto Mourão, Consuelo Fortes Santiago. 2. ed. Belo Horizonte: Editora UFMG, 2014.

COSSON, R. Entre o cânone e o mercado. In: PAULINO, Graça; COSSON, Rildo (Org.) Leitura literária: a mediação escolar. Belo Horizonte: Faculdade de Letras da UFMG, 2004. p. 93-98.

DALVI, M. A. Literatura na escola: propostas didático-metodológicas. In: DALVI, M. A.; REZENDE, N. L.;JOVER-FALEIROS, R. (Org.). Leitura de literatura na escola. São Paulo: Parábola, 2013.p. 67-97 FRANCHETTI, P. Apresentação. In: QUEIRÓS, E. de. O primo Basílio. 1. ed. Cotia: Ateliê Editorial, 1998. p. 9-44

GUEDES, D. Jorge Amado segundo a crítica literária. Disponível em: <http://jconline.ne1o.uol.com. $\mathrm{br} / \mathrm{canal} /$ cultura/literatura/noticia/2012/o8/o4/jorge-amado-segundo-a-critica-literaria-51532. php>. Acesso em: 24 maio 2015.

MAIA, J. D. Português. 6. ed. São Paulo: Ática, 2004. NICOLA, J. de. Português: Ensino Médio. 1. ed. São Paulo: Scipione, 2005. v. 2.

PERRONE-MOISÉS, L. Literatura para todos. Literatura e sociedade - Revista do Departamento de Teoria Literária e Literatura Comparada da USP, São Paulo, n. 1, p. 16-29, 2006. 
REZENDE, N. L. O ensino de literatura e a leitura literária. In: DALVI, M. A.; REZENDE, N. L.; JOVER-FALEIROS, R. (Org.). Leitura de literatura na escola. São Paulo: Parábola, 2013. p. 99-112 SOUZA, R. A. A ideia de história da literatura: constituição e crises. In: MOREIRA, M. E. (Org.).

Histórias da literatura: teorias, temas e autores. Porto Alegre: Mercado Aberto, 2003. p. 141-156 TAKAZAKI, H. H. Língua portuguesa: Ensino Médio. 2. ed. São Paulo: IBEP, 2005. Volume único. TORRALVO, I. F.; MINCHILlO, C. A. C. Linguagem em movimento. São Paulo: FTD, 2010. v. 1.

\section{SOBRE O AUTOR}

Júlio de Souza Valle Neto é bacharel e licenciado em Letras pela Universidade Estadual de Campinas, tendo obtido os títulos de Mestre e Doutor em Teoria e História Literária pela mesma Universidade. Atualmente é professor adjunto da Escola de Filosofia, Letras e Ciências Humanas da Universidade Federal de São Paulo, câmpus Guarulhos.

E-mail: juliovalleunifesp@gmail.com

Recebido em 11 de novembro de 2015 e aprovado em 02 de agosto de 2016. 